Sādhanā Vol. 38, Part 5, October 2013, pp. 1051-1064. (C) Indian Academy of Sciences

\title{
Development of human resources for Indian nuclear power programme
}

\author{
$\mathrm{R} \mathrm{B} \mathrm{GROVER}^{1, *}$ and R R PURI ${ }^{2}$ \\ ${ }^{1}$ Homi Bhabha National Institute, Anushaktinagar, Mumbai, 400 094, India \\ ${ }^{2}$ Formerly with Bhabha Atomic Research Centre and Homi Bhabha National \\ Institute, Anushaktinagar, Mumbai, 400 094, India \\ e-mail: rbgrover@hbni.ac.in
}

\begin{abstract}
The continuing research and development on nuclear technology by research establishments in the country and maturing of Indian industry have brought the nuclear energy programme in India to a stage where it is poised to take a quantum leap forward. The vision of expansion of nuclear power also requires a wellstructured specialized human resource development programme. This paper discusses the requirements of the human resource development programme for nuclear energy, the challenges in the way of its realization, its national and international status and traces the history of nuclear education in the country. It brings out the linkage of human resource development programme with the nuclear energy programme in the country. It also describes the initiatives by the university system in the area of nuclear education and support provided by the Department of Atomic Energy to the university system by way of extra-mural funding and by providing access to research facilities.
\end{abstract}

Keywords. Nuclear education; human resource development; nuclear knowledge management; nuclear energy.

\section{Introduction}

Energy acts as a multiplier for human efforts and as a result there is a strong correlation between Gross Domestic Product of a country and its energy consumption. It is, therefore, not surprising that today the world is engaged in relentless search for finding newer sources of energy and the efficient use of the known ones. It is an issue that occupies high priority in scientific and technical research supported liberally by policy makers around the globe. Nuclear energy from fission has been around for about six decades and continues to be an important part of the energy mix of several countries. Also, many more countries are looking at setting up nuclear power plants. In parallel, international collaborative efforts are in full swing to find ways of harnessing fusion energy. Presently, nuclear power, therefore, refers to the power produced by the

*For correspondence 
process of nuclear fission. It was deployed initially in large measures by advanced economies having well-established knowledge infrastructure. A defining characteristic of nuclear power is the possible support it can provide to nuclear weapons programme in the country. This has led to formulation of a global regime governing nuclear power resulting in its cautious expansion to countries outside the select few. Additionally, power of the atom was first demonstrated to public by nuclear weapons and this has shaped public perception towards a cautious acceptance of nuclear energy. Moreover, perceived notions of ill effects of low dose nuclear radiation, disposal of high-level nuclear waste and occurrence of a few high consequence events have created concerns in the public mind that need to be addressed. As a result, the expansion of nuclear power in many countries has gone through ups and downs. It is, however, witnessing a comeback since last few years. So much so that even small countries, as also oil rich countries, are opting for nuclear power. Countries around the world have been continuously tuning their nuclear power policies considering energy demand and supply situation, their energy resource position, climate change issues and public perception. India is not endowed with significant energy sources and so has been steadfast in its support for nuclear power and has unwaveringly pursued closed fuel cycle so as to extract full energy potential of its moderate uranium resources and also to exploit its vast resources of thorium.

It must be mentioned that nuclear power programme is one application of nuclear technology; the medical, agricultural, and industrial applications and use of nuclear radiation in food preservation are amongst the others.

Needless to say, implementation of any programme requires knowledgeable and skilled manpower. The knowledge and skills are imparted in universities, polytechnics and dedicated training centres. It would appear that the question of development of manpower for any new technology would be one of incorporating appropriate curricula at various levels of education and training. However, some technologies such as nuclear, aerospace and computer to name a few, are knowledge-intensive and, therefore, manpower training requires intense efforts. Additionally, issues arising out of radiation and nuclear safety, physical protection of nuclear materials and facilities, and safeguards to prevent diversion of nuclear material require special precautions, not easily implementable in educational institutes, particularly in our country. Nuclear technology is multidisciplinary and any university or institute would require vast faculty resources for conducting nuclear education. The human resource development for nuclear energy, therefore, demands special attention. Not surprisingly, International Atomic Energy Agency (IAEA) is also paying serious attention to, not only promoting nuclear education, but also to coordinating attempts for formulation and implementation of courses for nuclear education.

The Human Resource Development requires education and training at various levels. In this article, we restrict ourselves to the issue of manpower development appropriate for undertaking Research \& Development (R\&D) and supervisory level Operation and Maintenance tasks. This requires education at graduate level and beyond. We, therefore, begin by discussing the status of nuclear education at that level (section 2). As we will see, since the inception of nuclear energy programme close to six decades ago, because of complexities mentioned in the previous paragraph, the Department of Atomic Energy (DAE) had to shoulder efforts for conducting nuclear education. In section 3 we, therefore, give detailed description of the nuclear education and training programmes of DAE and section 4 describes its initiatives to support education and research in universities. The concluding remarks are given in section 5 .

It is also pertinent to remark that to support economic growth, electricity generation in the country has to increase manifold (Grover \& Chandra 2006) and overall vision of the DAE is to increase nuclear installed capacity based on uranium-plutonium cycle to a level where nuclear 
contribution to the national grid is about $25 \%$ of total electricity generation within next four to five decades (Grover 2013). Twelfth five year plan lays emphasis on developing multiple options for growth of nuclear power to provide energy security in an environmentally friendly manner. Projections have been made from time to time by the DAE and in an exercise done in 2006, it was projected that in the coming decade to take care of replacement of personnel retiring and to provide manpower for expansion of the programme, it would be necessary to train and recruit about 700 scientists and engineers every year in R\&D units and about 650 engineers every year in Public Sector and Industrial Units.

\section{Status of nuclear education}

Teaching of nuclear science and engineering requires vast infrastructure and in many cases, supervision by a national nuclear regulatory authority. Teaching of basics of application of nuclear radiation for tasks in agriculture, industry, medicine and food processing is in altogether different category than what is required for nuclear power plants. Nuclear power programme involves design, development and construction of nuclear reactors and related fuel cycle facilities, the use of nuclear radiation needs supply and knowledge of safe use of sources of radiation. Hence, it is the development of human resource for nuclear science and engineering of nuclear power plants and related fuel cycle facilities which is most challenging. Those challenges are universal and hence attract global attention (see IAEA Series on Status and Trends in Nuclear Education 2011). In what follows, nuclear education refers to its said challenging aspect.

First question that may be asked in this regard is: at what level of university education should the nuclear engineering be introduced. One school of thought is that it be introduced at Bachelor's degree level whereas the other school of thought advocates its introduction as a specialization at Master's degree level. Nuclear engineering is taught as a specialization at Bachelor's degree level in many universities in the United States. However, the utility of such graduates is reported by the nuclear industry as far from satisfactory. ${ }^{1}$ One may regard nuclear engineering as a specialized application of core engineering disciplines like mechanical, chemical, electrical, metallurgy and civil, keeping in view the interaction of the basic discipline with nuclear, atomic and reactor physics. It is our belief that under-graduate education should be in a broad based discipline, and specialisation like nuclear science and engineering should be at Master's level. This approach ensures that wide job choices are available to an individual based on under-graduate qualification and not be limited by a narrow specialisation.

The supporting technical manpower for nuclear programme can be channelled through suitably designed training programmes at various levels in polytechnics and by in-house training programmes in the nuclear industry.

The university system in USA and Europe has been conducting nuclear engineering education for several decades now. Although the nuclear energy programme in India is close to six decades old, interest by universities has been lukewarm. The nuclear education in India has so far been conducted mainly by the Department of Atomic Energy (DAE) of India. Table 1 lists the institutions engaged in nuclear education in India and a brief description of their nuclear engineering and science programmes is given below.

\footnotetext{
${ }^{1}$ The second author participated in the IAEA meeting on Status and Trends in Nuclear Education held during May 4-8, Vienna, (2009) and this aspect was discussed during the meeting.
} 
Table 1. Institutions in India awarding degrees in nuclear engineering and science.

\begin{tabular}{lll}
\hline Institution & \multicolumn{1}{c}{ Courses } & Degrees awarded \\
\hline Homi Bhabha National Institute & Nuclear Engineering, Physics, & M.Tech./M.Phil./ \\
(HBNI) & Chemistry, Biosciences, & M.Sc.(Eng.), Ph.D., \\
& Mathematics, Nuclear Medicine, & Post Graduate \\
& Radiological Physics & diploma \\
Indian Institute of Technology, Kanpur & Nuclear Engineering and Technology & M.Tech./Ph.D. \\
University of Delhi & Nuclear Science and Technology & M.Tech. \\
Jadavpur University & Nuclear Engineering & M.E. \\
Pandit Deendayal Petroleum University & Nuclear Engineering & M.Tech. \\
Indian Institute of Technology, Madras & Nuclear Engineering & M.Tech. \\
\hline
\end{tabular}

(i) Established in 1957, Training Schools of DAE have been imparting nuclear education and remain the main centres for nuclear human resource development in India. Since 2006, the academic programmes of Training Schools are being conducted under the aegis of Homi Bhabha National Institute (HBNI), a deemed to be university funded by DAE. In parallel, Institute for Plasma Research also runs a one year programme for training in fusion science. The details of those are discussed in the next section.

(ii) Besides DAE, the Indian Institute of Technology, Kanpur (IIT, Kanpur) is the only other institution in the country which has been conducting Nuclear Engineering and Technology programme for a long time. It offers M.Tech. and Ph.D. degrees in the area of Nuclear Engineering and Technology. While the programme has been running for a long time, a very small percentage of its graduates have joined nuclear establishment in the country.

(iii) Started in 2008, the Nuclear Science and Technology programme at University of Delhi is of three years duration for those holding Bachelor's degree in Physics leading to the award of M.Tech. in Nuclear Engineering. Two batches have graduated so far and a good percentage of the graduates of both the batches have been selected for the Ph.D. programme of HBNI.

(iv) The M.Tech./M.E. programmes in Nuclear Engineering were started in Jadavpur University, Jadavpur, Pandit Deendayal Petroleum University, Gandhinagar and Indian Institute of Technology, Madras during last three to four years.

Besides programmes at post-graduate level, many institutes such as IIT Roorkee offer courses in nuclear science and engineering at under-graduate level.

Though it would be premature to judge recent initiatives on nuclear education in the university system in the country, it nevertheless appears that it will take a long time to make any impact. The reasons are:

(i) Availability of faculty for nuclear subjects is highly inadequate. The universities either seek the support of DAE for teaching nuclear subjects or are dependent on persons retired from DAE.

(ii) Jobs for those who have qualified in nuclear science and engineering are presently offered only in DAE. While DAE provides avenues for recruitment at all levels, selection benchmarks are very rigorous resulting in low selection percentage. Those not selected have, in some cases, difficulty in getting employment. The nuclear education in the university system will become attractive once further expansion of nuclear industry takes place 
throwing open the opportunities for qualified nuclear professionals in private sector (consultancy organisations and manufacturing firms).

(iii) Absence of laboratories related to nuclear engineering subjects and inaccessibility to other related facilities makes the university system look up to DAE for support in this regard.

(iv) Inadequate educational material particularly text books on nuclear related subjects.

Some of the difficulties mentioned above are addressed by several measures being taken at national and international level to promote nuclear education like the following.

(i) The IAEA is taking initiative to encourage writing of books on nuclear related topics and arranging its distribution in e-form. It has already distributed a couple of such books to member states.

(ii) Realizing the shortage of competent faculty for nuclear education, IAEA is supporting initiatives for web-based nuclear education. The formation of Asian Network for Education in Nuclear Technology (ANENT) to coordinate nuclear education in Asia, and to set-up web-based nuclear education was its one such initiative. Similarly, European Network for Education in Nuclear Engineering (ENENE) is an initiative to coordinate nuclear education among universities in Europe.

(iii) In India, DAE supports nuclear education in universities by deputing its faculty to teach specialized courses. It has made offers to train the teachers from university system in nuclear subjects, but so far no one has accepted the offer.

(iv) Through the Board of Research in Nuclear Sciences (BRNS), DAE provides extra mural funding and technical support for projects in universities in the frontline areas of research and in the areas of relevance to its programme.

(v) Research reactors and accelerator facilities available in various DAE units are made accessible to the universities in the country through the University Grants Commission-DAE Consortium for Scientific Research (UGC-DAE-CSR). Inter University Accelerator Centre located in New Delhi set-up by UGC also offers its facilities to university researchers.

(vi) Through the academic programmes of HBNI, from post-graduate diplomas to the doctoral level, DAE is contributing to development of manpower for nuclear and related tasks.

Details of the said programmes are given in the next section.

\section{Nuclear education and training by DAE}

\subsection{Background and history}

In India, nuclear education and research began with the setting-up of the Tata Institute of Fundamental Research (TIFR), Mumbai, in 1945. To provide a legal framework for exploitation of nuclear technology, Atomic Energy Act was passed on April 15, 1948 and Atomic Energy Commission was constituted on August 10, 1948. The Department of Atomic Energy was created on January 3, 1954. Several research activities were started as part of what was then called Atomic Energy Establishment, Trombay (AEET) and later renamed Bhabha Atomic Research Centre (BARC). In 1962, Atomic Energy Act, 1948 was replaced by Atomic Energy act, 1962.

No university in the country was conducting any academic programme in nuclear engineering and science at the time the nuclear energy programme was started in India. In order to meet the manpower requirements for the atomic energy programme, AEET Training School (now called BARC Training School) was set-up to train and recruit the engineering and science graduates into the DAE. Though it was not affiliated to any university, it was structured as a Master's level 
specialization for engineering and science graduates. The faculty was mainly the practicing professionals. That approach proved successful and is being pursued to date. Devising ways and means to transmit not only explicit but also implicit and tacit $^{2}$ knowledge of nuclear technology is a concern of nuclear knowledge management (IAEA TECDOC 2012). The practicing professionals as faculty helps in addressing this concern as they are well-versed in all facets of nuclear knowledge: explicit, implicit as well as tacit. However, its in-house academic programme by itself is not the only reason for the success story of the human resource development (HRD) programme of DAE. Emphasis on openness to the academic world practiced by DAE ensures that its in-house HRD programme continues to be contemporary. Extensive linkages with the academia continue to breathe life in to the R\&D activities of DAE. It is achieved through various means including providing opportunities to its researchers to improve qualifications, lateral induction of persons with higher qualifications, and academic collaboration with and research funding to universities and academic institutions.

In addition, Nuclear Power Corporation of India Limited (NPCIL) runs its own Nuclear Training Centres at Tarapur in Maharashtra, Rawatbhata in Rajasthan, Kaiga in Karnataka, Kalpakkam and Kudankulam in Tamil Nadu. This programme is oriented towards development of manpower for operation and maintenance of nuclear power plants and has been very useful in meeting requirements of NPCIL.

Institute for Plasma Research also runs a Technical Training Programme as a pre-induction training programme for employees.

TIFR has been running a very successful Ph.D. programme right from its inception and has expanded its programme after becoming a deemed to be university. Further expansion of programmes will take place at its Hyderabad campus which is being set-up. Over the years several grant-in-aid institutions have become a part of DAE and this has led to expansion of human resource development activities of DAE. Further expansion of academic programmes is taking place with the setting up of Homi Bhabha National Institute (HBNI), a deemed to be university under the governance of DAE. A brief description of HBNI, programmes for lateral induction, extra-mural funding and other initiatives follows.

Right from the inception of the atomic energy programme, the DAE has been conscious of the fact that pursuit of nuclear power is a knowledge intensive endeavour, and this consciousness is embedded in its day to day working. Examples include procedure for recruitment and training of scientists and merit based promotion. Rigorous screening and interview process for promotions ensure that an employee keeps himself or herself up to date in the area of his/her expertise. Reports written on design or operation of nuclear facilities are subjected to multi-tier peer review by expert committees and such a peer review while ensuring safety of the facilities, also continuously hones design and analysis skills of employees.

\subsection{Homi Bhabha National Institute}

The setting-up of the Homi Bhabha National Institute is a recent initiative of DAE. It provides an umbrella for academic programmes run by ten institutions of DAE. We describe below its genesis and academic programmes.

\footnotetext{
${ }^{2}$ The knowledge which can be codified (like in the form of documents, database, etc.) is called explicit and that which can not be codified is called tacit. However, some people include implicit knowledge as a class between explicit and tacit knowledge as the one which can be codified but has not yet been.
} 
3.2a Rationale and structure: Various institutions of DAE have been running academic programmes for several years. Some of these programmes were affiliated to universities located near to the institutions and some like that at BARC Training School were not affiliated to any university. Over the years, a need was felt to create a mechanism to bring all academic programmes under one umbrella and use them to create linkages among various institutions of the department. It was also felt that faculty and physical research infrastructure available within the Department could also be used for human resource development for the country. Towards this objective, the Homi Bhabha National Institute was set-up in 2005 as a deemed to be university by bringing together academic programmes of ten institutions of the DAE. It has a distributed structure and is now geared towards providing academic programmes in nuclear science and engineering, mathematics and oncology.

HBNI comprises of the following ten units of DAE as its Constituent Institutions (CIs).

(i) R\&D Centres:

1. Bhabha Atomic Research Centre (BARC), Mumbai, Maharashtra

2. Indira Gandhi Centre for Atomic Research (IGCAR), Kalpakkam, Tamil Nadu

3. Raja Ramanna Centre for Advanced Technology (RRCAT), Indore, Madhya Pradesh

4. Variable Energy Cyclotron Centre (VECC), Kolkata, West Bengal

(ii) Grant-in Aid Institutions:

1. Saha Institute of Nuclear Physics (SINP), Kolkata, West Bengal

2. Institute for Plasma Research (IPR), Gandhinagar, Gujarat

3. Institute of Physics (IoP), Bhubaneswar, Odisha

4. Harish-Chandra Research Institute (HRI), Allahabad, Uttar Pradesh

5. Tata Memorial Centre (TMC), Mumbai, Maharashtra

6. Institute of Mathematical Science (IMSc), Chennai, Tamil Nadu

The role of HBNI is to nurture in-depth capabilities in nuclear science and engineering and to serve as a catalyst to accelerate the pace of basic research and facilitate its translation into technology development and applications through academic programmes, viz., Master's and Ph.D. degrees in Engineering, Physical, Chemical, Mathematical, Life and Health Sciences while encouraging inter-disciplinary research. Additionally, a Strategic Studies programme has also been identified to ensure availability of adequate qualified human resources to address issues pertaining to nuclear law, economics of nuclear power, nuclear security, nuclear proliferation, intellectual property rights, etc.

In 2006, the Government of India decided to strengthen science education and set-up institutions for science education and research in various parts of the country. One such institution, the National Institute for Science Education and Research (NISER) was set-up at Bhubaneswar by the DAE as a project of the Institute of Physics. Academic programmes of this institute were started as a part of IoP and thereby under HBNI. Steps are being taken to make NISER an independent Constituent Institution (CI) of HBNI.

3.2b Academic programmes: HBNI offers a range of academic programmes. Except for NISER, which conducts integrated M.Sc. programme, all others institutions conduct programmes at Master's level. Various programmes offered by HBNI are the following.

- Ph.D. in varied disciplines is offered at all CIs. HRI and IMSc also offer an integrated M.Sc.- Ph.D. programme. 
- M.Tech. in engineering science, and M.Phil. in physical sciences, chemical sciences and life sciences. These programmes consist of one year of course work and one year of project work. The course work is offered at all campuses of BARC Training School and project work is offered at BARC, IGCAR, RRCAT, VECC and some other units of DAE. Those who do not wish to do project work get a diploma in lieu of an M.Tech. or an M.Phil.

- M.Sc. (Engg.) in which research content is more than that in M.Tech. programme. The duration of the project work under this programme is one-and-half year, while the duration of the course work is up to one year. This programme is offered at BARC, IGCAR, VECC and RRCAT and has been tailored for the employees of the Department.

- Integrated M.Sc. of five-year duration at NISER.

- Super Specialty Courses at TMC

- D.M. (Medical Oncology)

- M. Ch. (Surgical Oncology)

- M. Ch. (Gynaecological Oncology)

- Post Graduate Courses at TMC

- M.D. (Pathology)

- M.D. (Anaesthesiology)

- M.D. (Radio-diagnosis),

- M.D. (Radiotherapy),

- M.D. (Microbiology), and

- M.D. (Immuno-Haematology \& Blood Transfusion)

- DRM: Diploma in Radiation Medicine at BARC.

- M.Sc. (Nursing) at TMC

- Dip.R.P.: Diploma in Radiological Physics at BARC.

- DMRIT: Diploma in Medical Radio Isotope Techniques at BARC.

- In addition, the TMC also offers a two-year Certified Fellowship programme in 23 different disciplines related to Oncology.

Some of the scientific officers working in R\&D centres have been selected as faculty based on criteria similar to what is followed in other elite institutes in India. Rigour of the process can be judged from the fact that the percentage of scientists selected is about $10 \%$. Since the grant-inaid institutes which are the CIs of HBNI are academic institutes where the faculty appointments are done by following appropriate process, all the faculty members in those CIs are, therefore, recognized as the HBNI faculty.

It is worth mentioning that Ph.D. programme of HBNI is quite vibrant. The best part of the Ph.D. programme is that problems for research work are identified by the research supervisors based on what they encounter in day to day working. Interdisciplinary topics for research are encouraged. Ph.D. programme lays emphasis on course work, general comprehensive examination, and annual reviews by student-specific doctoral committees. The Institute offers a unique $\mathrm{Ph} . \mathrm{D}$. programme where students are encouraged to work at the interface of basic research and technology development. Under this programme, they work under the guidance of two supervisors, one having strength in basic research and the other in technology development. Two supervisors can be from across the CIs of HBNI and this has created one more channel to strengthen linkages between CIs. Just prior to the beginning of the admission process for the academic year in August 2013, around 1500 students are enrolled for Ph.D. and about 230 have 
already received $\mathrm{Ph} . \mathrm{D}$. HBNI is making special efforts to encourage engineers to enrol for $\mathrm{Ph} . \mathrm{D}$. and number of engineers enrolled is about 300 and 7 engineers have already completed Ph.D.

Academic programmes at BARC Training Schools can be described as flagship programmes of the Department and have been singularly responsible for the success of nuclear power programme in the country and are described in detail next.

3.2c Academic programmes in BARC training schools: The programmes at BARC Training Schools prepare engineering graduates and science post-graduates for a career as professionals in nuclear science and engineering in DAE. Training School programme was launched in 1957 at the Training School, Mumbai. Though named Training School, it essentially conducts post graduate level academic programmes in nuclear science and engineering. As the programmes of the Department started expanding, the need was felt to establish more Training Schools to cater to the human resource requirements in varied specializations. As a result, Training Schools were set-up at the DAE units appropriate for the intended specialization and presently Training Schools are functioning as follows:

(1) At Bhabha Atomic Research Centre, Mumbai (since 1957) — for specialisation in nuclear and related sciences and technologies.

(2) At Raja Ramanna Centre for Advanced Technology, Indore (since 2000) — for specialisation in engineering physics (lasers, accelerators, cryogenics, superconductors, material science, power electronics and microwaves).

(3) At Nuclear Fuel Complex, Hyderabad (since 2001) - for design, engineering, construction, operation and maintenance of chemical plants (production of heavy water and fuel fabrication).

(4) At Indira Gandhi Centre for Atomic Research, Kalpakkam (since 2006) — for specialization in fast breeder reactor and recycle science and technology.

(5) At Atomic Minerals Directorate for Exploration and Research, Hyderabad (since 2010) for specialization in geophysics and geology related to uranium and other atomic minerals.

Selection for admission to Training Schools is based on a written test for screening followed by a selection interview. The interview process is very rigorous. This can be judged by the fact that the selection percentage is less than $15 \%$. The selection process is centralised to ensure uniformity of quality across all schools.

The programme comprises one year of academic courses at one of the BARC Training Schools and prepares students in their respective disciplines to take up diverse assignments in the units of the department; assignment could involve basic and applied research, design, development and deployment of nuclear science and engineering. Those completing the one year course work successfully are absorbed as Scientific Officers. After joining DAE, the students can undertake one year project work leading to the award of M.Tech. or M.Phil. So far over 7000 students have graduated from the Training Schools since 1957, and about 450 students have gone on to complete M.Tech. or M.Phil. since the setting up of HBNI. The Training Schools have ensured self-reliance and sustainability of the Indian nuclear energy programme. Almost all leadership positions in various units of the Department to date have been occupied by the graduates from this programme.

3.2d Programmes for lateral entrants: There are several well running academic programmes at the post-graduate level in the country and to take benefit of those programmes, DAE has 
provision for induction and training of such graduates. One programme, called DAE Graduate Fellowship Scheme (DGFS) for M.Tech. aims to derive benefit from well run M.Tech. programme at IITs and other elite universities and institutions. The other programme, called K.S. Krishnan Associateship Programme, aims to induct candidates who have completed Ph.D. in sciences or engineering from any university in India or abroad or are engaged in research and development after M.Tech.

Students who have been selected for Training School and also selected by one of the several elite institutions (IITs at Bombay, Madras, Delhi, Kanpur, Kharagpur, Roorkee, or IT-BHU Varanasi or NIT Rourkela or Institute of Chemical Technology, Mumbai) for their M.Tech. programme in a discipline of interest to DAE can join DGFS. Such students get a stipend much higher than normal stipend for M.Tech. students and all the expenses to pursue M.Tech. They pursue course work for M.Tech. at the said institutes and then work on a project of interest to the programmes of DAE under the supervision of faculty from the institute and a unit of DAE. On successful completion of M.Tech., the DGFS fellows are recruited in DAE as scientific officers and study nuclear engineering for one semester in BARC.

Under K.S. Krishnan Research Associateship programme candidates having Ph.D. in science or engineering or M.Tech. with two years R\&D experience are selected, after a selection process consisting of screening based on publication record and a rigorous interview. Selected candidates carry up to two years of research work as associates, attend nuclear related courses as desired and are offered employment in DAE based on an assessment during the two years. Over the years, the rigour of the selection process has been so tuned that all those selected as Associates are eventually absorbed as scientific officers in any of the research centres of the department. In a few cases associates have been absorbed in Atomic Energy Regulatory Board as well.

3.2e Collaborations: HBNI has also become a vehicle for DAE to collaborate with universities and research centres in the country and abroad. Collaboration has been formalised by signing Memoranda of Understanding (MoU). Such MoUs have been signed even with foreign universities and research centres. Universities abroad find it expedient to collaborate with a university rather than a nuclear research centre. Typically MoUs provide for academic collaborations by exchange of credits and joint supervision of research students. MoUs have been signed with the following institutions: Indian Institute of Technology, Bombay, Mumbai, Indian Institute of Technology, Madras, Chennai, Tata Institute of Fundamental Research, Mumbai, Institute of Chemical Technology, Mumbai, Jadavpur University, Jadavpur, Indian Statistical Institute, Kolkata, CEA, France, University of Virginia, USA, Indian Institute of Science, Bangalore, The University of Texas at Austin, USA, University of North Texas, USA.

3.2f Radiological safety and radiation medicine: For safe exploitation of nuclear technology it is necessary to train human resource in radiation safety and towards this, BARC has been running a Diploma in Radiological Physics (Dip.R.P.) programme for over five decades. It is one year programme to train candidates having Master's degree in Physics for radiological applications. The Dip.R.P. holders are in great demand for overseeing the working of radiological units in the country. In view of large demand for radiation safety professional, programmes have now been started by some universities as well. All other programmes offer M.Sc. in radiological physics.

BARC pioneered nuclear medicine in the country and has been running a Diploma in Radiation Medicine (DRM) programme. It is two years programme and the entry level qualification for 
Table 2a. Short-term industrial radiation safety related training courses conducted by BARC.

\begin{tabular}{|c|c|c|c|}
\hline Sr. No. & Name of the course & Duration & Eligibility \\
\hline 1. & $\begin{array}{l}\text { Radiation safety aspects for RSO } \\
\text { in Nucleonic Gauges (NG) }\end{array}$ & 7 days & $\begin{array}{l}\text { Degree in Science or Degree/ } \\
\text { diploma in engineering }\end{array}$ \\
\hline 2. & $\begin{array}{l}\text { Radiation safety aspects for } \\
\text { Radiological Safety Officer (RSO) } \\
\text { in Research Applications (RA) }\end{array}$ & 7 days & $\begin{array}{l}\text { Degree in Science } \\
\text { (Sponsored candidates only) }\end{array}$ \\
\hline 3. & Industrial radiography testing level-I (RT-1) & 15 days & $\begin{array}{l}10+2 \text { with science/ } \\
\text { Diploma in engineering and } \\
6 \text { months working experience }\end{array}$ \\
\hline$* 4$. & Industrial radiography testing level-II (RT-2) & 15 days & RT- $1+$ three years experience \\
\hline 5. & $\begin{array}{l}\text { Radiation safety aspects for RSO } \\
\text { in Radiation processing facilities }\end{array}$ & 3 months & Degree in Science \\
\hline$* 6$ & $\begin{array}{l}\text { Radiation safety aspects for operators } \\
\text { in Radiation processing facilities }\end{array}$ & 3 months & Degree in Science \\
\hline
\end{tabular}

*In collaboration with Board of Radiation and Isotope Technology

the programme is Bachelor of Medicine and Bachelor of Surgery (MBBS). Technicians working in nuclear medicine centres also need training and to provide needed training, BARC runs a Diploma in Medical Radioisotope Techniques (DMRIT) programme. It is a one-year programme and the entry level qualification for the programme is Bachelor of Science (B.Sc.).

In addition, BARC conducts several short term training programmes and courses as detailed in tables $2 \mathrm{a}$ and $\mathrm{b}$.

3.2g Future directions: Accredited as a deemed to be university in 2005, HBNI has already been reviewed by University Grants Commission (UGC) as well as Ministry of Human Resource Development. All academic programmes including research based academic programmes are now well-established. Post-graduate medical programmes running at Tata Memorial Hospital

Table 2b. Short-term medical radiation safety related training courses conducted by BARC.

\begin{tabular}{|c|c|c|c|}
\hline Sl. No. & Name of the course & Duration & Eligibility \\
\hline 1. & $\begin{array}{l}\text { Radiation Safety for Radiation } \\
\text { Therapy Technologist (RTT) }\end{array}$ & 7 days & $\begin{array}{l}\text { (i) } 10+2 \text { with Science and } \\
\text { (ii) } 2 \text {-years radiation therapy } \\
\text { technologists course or } 5 \text { years } \\
\text { working experience as RTT }\end{array}$ \\
\hline 2. & $\begin{array}{l}\text { Radiation Safety in Servicing of } \\
\text { Radiotherapy Equipments (SRT) }\end{array}$ & 7 days & $\begin{array}{l}\text { (i) Degree/ Diploma in electrical/ } \\
\text { electronic/ biomedical/ } \\
\text { mechanical engineering } \\
\text { (ii) one-year working experience }\end{array}$ \\
\hline 3. & $\begin{array}{l}\text { Radiation Safety and Quality Assurance } \\
\text { in Diagnostic Radiology (QADR) }\end{array}$ & 7 days & $\begin{array}{l}\text { (i) Qualified X-ray radiographer } \\
\text { (ii) Qualified X-ray service engineer }\end{array}$ \\
\hline 4. & $\begin{array}{l}\text { Orientation and Certification Course } \\
\text { for RSO (Medical) }\end{array}$ & 10 days & $\begin{array}{l}\text { Qualified Medical Physicist } \\
\text { [M.Sc. (Med. Phys.) with more } \\
\text { than 50\% marks] }\end{array}$ \\
\hline 5. & $\begin{array}{l}\text { Certification examination for RSO } \\
\text { in Nuclear Medicine }\end{array}$ & 3 days & DRM/ DMRIT or equivalent \\
\hline
\end{tabular}


have been considerably expanded. Now it is time to increase intake to the $\mathrm{Ph}$.D. programmes at all CIs. Experimental infrastructure available with DAE institutions is vast and can be effectively used to train human resources for the needs of DAE as well as for other sectors in the country. HBNI is, therefore, working to increase enrollment of students pursuing Ph.D. This will be useful to DAE as a good doctoral student delivers a lot through a Ph.D. thesis and subsequent to completing his Ph.D. is ready to work in a unit of DAE or any other elite institution in the country. This requires setting up facilities such as students' hostel and this is being done.

HBNI has already been instrumental in furthering academic collaborations. Setting up of a Global Centre for Nuclear Energy Partnership by DAE in Haryana near New Delhi is likely to provide further impetus to collaborations with other countries. The land for this centre has been acquired and construction is expected to commence in the second half of 2013.

\section{Supporting research in universities by way of extra mural funding and by providing access to the research facilities of DAE}

The DAE values immensely its linkage with universities. The desired linkage with universities is established by

(i) supporting projects of its interest in universities by extra mural funding disbursed by Board of Research in Nuclear Sciences (BRNS) and National Board for Higher Mathematics (NBHM),

(ii) by providing access to universities to use its research facilities through UGC-DAE Consortium for Scientific Research,

(iii) offering opportunity to undergraduate engineering students to do project work in BARC, and

(iv) establishment of National Initiative on Undergraduate Science (NIUS) and Olympiad training Programmes,

\subsection{The Board of Research in Nuclear Sciences $(B R N S)^{3}$}

The Board of Research in Nuclear Sciences (BRNS) in its original form was set-up in 1945 as Atomic Energy Committee under the aegis of the Council of Scientific and Industrial Research (CSIR). It was re-designated in 1946 as the Atomic Research Committee (ARC) and then once again reconstituted as Board of Research in Atomic Energy (BRAE). In the year 1955-56, BRAE was replaced by the Board of Research in Nuclear Sciences (BRNS). In its early years, the BRNS or, for that matter, its precursor BRAE, was the only agency in the country funding research projects in the Universities. This unique position held by BRNS changed when CSIR extramural research funding became available, and the Department of Science and Technology (DST) emerged as a major government agency extending research support to all branches of Science and Technology. As a result, research funding by BRNS could be directed more towards research relevant to the needs of the Department of Atomic Energy.

The Board of Research in Nuclear Sciences (BRNS) is presently an advisory body of the DAE which recommends financial assistance to universities/institutions/laboratories with the

\footnotetext{
${ }^{3}$ This section is based on information compiled from several sources including minutes of the meetings of Atomic Energy Commission and Annual Reports of the DAE.
} 
objective to encourage and promote scientific research, organize symposia/workshops in areas of relevance to the mandate of the Department of Atomic Energy (DAE). BRNS plays a vital role in strengthening collaboration with educational institutions/universities to meet the scientific and the technological needs of the Department to fulfil its mandate. It also awards projects to young scientists to initiate them in a career of research. It has advisory committees to guide its working. The objectives of BRNS are to:

- Identify and fund R\&D programmes and projects,

- Award fellowships to pursue doctoral programmes,

- Award research grants to young scientists,

- Organise symposia on topics of relevance and interest to DAE as well as frontier areas of science,

- Extend financial support to symposia and conference organised by professional bodies and other agencies,

- Establish chairs in universities and other institutions of higher learning,

- Create infrastructure facilities for advanced research, and

- Identify and create centres of excellence.

The commitment of DAE to the cause of BRNS can be judged from the fact that its annual budget has increased from about Rs. 11 crores in 1998 to about Rs. 83 crores today.

\subsection{National board for higher mathematics (NBHM)}

The National Board for Higher Mathematics promotes education and research in higher mathematics at the post graduate and doctoral levels by offering scholarships, supporting university libraries for acquiring mathematics books, and by funding mathematics conferences.

\subsection{Availability of research and experimental facilities}

The DAE facilities like Reactors and Accelerators are made available to the universities in the country through the UGC-DAE Consortium for Scientific Research. A significant number of students from different universities in the country come to the research centres of the Department for performing experiments, training and for their thesis work.

\subsection{Practical training and project work}

Under this programme, the BARC and other R\&D units of DAE support practical training and project work of engineering undergraduate and science post graduate students from universities all over the country. Working in state-of-the-art laboratories of the DAE research centre not only exposes the students to R\&D environment, but also motivates them to take up a career with DAE.

\subsection{National initiative on undergraduate science (NIUS) and Olympiad programmes}

DAE is supporting the cause of undergraduate education through its Homi Bhabha Centre for Science Education (HBCSE), Mumbai. Among other activities, HBCSE conducts programmes like the National Initiative on Undergraduate Science (NIUS). Under this programme, selected undergraduate students from all over the country spend their vacation period in HBCSE where 
they are taught courses and undertake project work with scientists from neighbouring academic and research institutes. HBCSE also coordinates the Olympiad programme and prepares students for International Olympiads in various disciplines.

\section{Conclusions}

Nuclear technology is multidisciplinary, knowledge-intensive, and its education and training are constrained by unusual measures demanded by the concerns about radiation and nuclear safety, physical protection of nuclear materials and facilities, and safeguards to prevent diversion of nuclear material. This requires vast faculty resources as also extraordinary and expensive infrastructure for conducting nuclear education making the task of human resource development in nuclear science and technology a challenging one. The human resource for the nuclear energy programme in India so far has been developed in-house in the DAE. However, large requirement of manpower to take forward the growing nuclear energy programme in the country can be met only by extending concurrently the reach of the human resource development activity in nuclear science and technology. The DAE is therefore supporting the university system in India, which is gearing up to the need of offering nuclear energy related courses. It may be emphasized that nuclear education, being a means of preservation and transmission of explicit knowledge, is just one component of nuclear knowledge management (NKM). The NKM also involves creation of mechanisms to preserve and transmit implicit and tacit knowledge. The steps outlined above will hopefully ensure, not only an uninterrupted delivery of knowledgeable and skilled manpower for the envisaged expansion of nuclear energy programme, but would also pave the way for developing a system for a wholesome nuclear knowledge management.

\section{References}

Grover R B 2013 Green growth and role of nuclear power: A perspective from India. Energy Strategy Reviews 1: 255-260

Grover R B and Chandra S 2006 Scenario for growth of electricity in India. Energy Policy 34: 2834-2847

Knowledge management for nuclear research and development organizations 2012 IAEA TECDOC-1675, Vienna

Status and Trends in Nuclear Education 2011 IAEA Nuclear Energy Series, No. NG-T-6.1, Vienna 